\title{
REPRODUCTIVE PERFORMANCE OF BROWN SWISS AND MESTIZO BOVINE IN HUMID TROPIC
}

\section{Desempeño reproductivo de bovinos brown swiss y mestizo en trópico húmedo}

\author{
R. Troncoso' (iD), C. Medina 2,3, J. Reátegui 2,3*iD
}

\footnotetext{
1 Universidad Nacional Amazónica de Madre de Dios. Tambopata, Madre de Dios, Peru.

2 Universidad Católica de Santa Maria, Arequipa, Peru

3 Centro Latino Americano de Estúdios de Problemáticas Lecheras (CLEPL) Arequipa, Peru.

* Corresponding author: Juan Reategui; email: jreategui@ucsm.edu. pe
}

Recibido: $01 / 03 / 2021$

Aceptado: 10/06/2021

Publicado: $13 / 08 / 2021$

\section{ABSTRACT}

The ability of ruminants to regulate body temperature depends on the genotype. Dairy breeds are generally more sensitive to heat stress than beef breeds. Higher-producing animals are more susceptible to heat stress because they generate more metabolic heat. The objective of evaluating reproductive performance as a response of adaptability to the management and climatic conditions of the Humid Tropics. 78 animals were used (40 Brown Swiss, from Puno and 38 Mestizas from local origin) raised in humid tropic conditions. Parametric statistics are presented as analysis of measures of central tendency and dispersion, non-parametric statistics by frequency analysis, the $\chi 2$ test of independence was used to detect differences, $\alpha=0.05$. The categorized and continuous dependent variables were evaluated with Student's t test using SPSS Software v.23. The mean age at first estrus in Brown Swiss was 12.43 months, in mestizo cattle 18.68 months $(P<0.05)$. Average age of first calving in Brown Swiss of 25.25 months versus mestizo cattle 28.34 months $(P<0.05)$. Interval from calving to the first service in Brown Swiss was 99.29 days. Open days observed in Brown Swiss was 107.29 days. The pregnancy rate at the first service in Brown Swiss was $70.0 \%$ pregnancy at the first service and $30.0 \%$ at the second service, for the mestizo genotype it was $68.4 \%$ at the first service, 28.9 at the second and 2.6 at the third service $(P>0.05 ; X 2=0.50 ; p=0.47)$. It is concluded that bovine animals of the Brown Swiss genotype have a good reproductive performance in the Humid Tropic climate compared to the Mestizo genotype.

Keywords: Reproductive performance, Brown Swiss, Humid tropics, Bovine

\section{RESUMEN}

La capacidad de los rumiantes para regular la temperatura corporal depende del genotipo- Las razas lecheras suelen ser más sensibles al estrés por calor que las de razas de carne. Los animales de mayor producción son más susceptibles al estrés por calor porque generan más calor metabólico. El objetivo de evaluar el desempeño reproductivo como respuesta de adaptabilidad a las condiciones de manejo y climáticas de Trópico Húmedo. Se utilizaron 78 animales (40 Brown Swiss, procedentes de Puno y 38 Mestizas de procedencia local) criados en condiciones de trópico húmedo. Los estadígrafos paramétricos se presentan como análisis de medidas de tendencia central y dispersión, los estadígrafos no paramétricos mediante un análisis de frecuencias, la prueba $\chi 2$ de independencia se utilizó para detectar diferencias, $\alpha=0,05$. Las variables dependientes categorizadas y continuas se evaluaron con $t$ de Student utilizando el Software SPSS v.23. La edad promedio a primer celo en Brown Swiss fue de 12,43 meses, en el ganado mestizo de 18,68 meses ( $P<0,05)$. Edad promedio del primer parto en Brown Swiss fue de 25,25 meses y en ganado mestizo 28,34 meses $(P<0.05)$. Intervalo del parto a la primera IA en Brown Swiss fue de 99,29 días. Días abiertos observados en Brown Swiss 107,29 días. La tasa de preñez al primer servicio en Brown Swiss fue de 70,0\% de preñez al primer servicio y $30,0 \%$ al segundo servicio, para el genotipo mestizo fue de $68,4 \%$ al primer servicio, 28,9 al segundo y 2,6 al tercer servicio $(P>0,05 ; X 2=0,50 ; p=0,47)$. Se concluye que, los animales bovinos del genotipo Brown Swiss tienen un buen desempeño reproductivo en el clima Trópico Húmedo comparado al genotipo Mestizos.

Palabras clave: Performance reproductivo, Brown Swiss, Trópico húmedo, Bovino 


\section{INTRODUCCION}

El ganado está sujeto a diversos tipos de estrés que afectan su reproducción, producción y salud. Hoy en día, el estrés por calor inducido por el medio ambiente y condiciones de manejo es motivo de gran preocupación debido a sus impactos perjudiciales sobre la performance del animal, especialmente para los animales de alta productividad. En las regiones tropicales, subtropicales y áridas, la alta temperatura ambiente es el factor principal que pone en peligro la reproducción y producción animal (Belhadj Slimen et al., 2016; Herbut et al., 2019; Bernabucci et al., 2010)

Los animales homeotermos tienen una zona termo neutral donde se mantiene la temperatura corporal normal y el gasto de energía es mínimo. La alta temperatura ambiental, la radiación solar y la velocidad del viento aumentan la temperatura efectiva del ambiente por encima de la zona termo neutral del ganado (Belhadj Slimen et al., 2016). Por lo tanto, la temperatura corporal del animal excede el rango especificado para su zona termo neutral, y la carga de calor total excede la capacidad del animal para disipar el calor (Bernabucci et al., 2010). Esta situación es llamada "estrés por calor", cuando la alta temperatura se acompaña de una alta humedad ambiental. Se ha discutido el efecto de la alta temperatura cuando es más pronunciado debido a la reducción de la disipación de calor por evapotranspiración (Bernabucci et al., 2010; Mader et al., 2007; Marai et al. ,2007). La carga de calor aumenta los problemas de salud y las tasas de mortalidad, especialmente para los animales intolerantes, de alta productividad y genotipos no adaptados a las condiciones climática del trópico (Belhadj Slimen et al., 2016).

El estrés por calor en medioambientes tropicales solía asociarse con una disminución de la síntesis de leche. Un enfoque meta analítico para evaluar el efecto de las temperaturas ambientales elevadas en la producción de leche concluyó que la disminución de la producción de leche podría resultar de los efectos acumulativos del estrés por calor en la ingesta de alimento, el metabolismo y la fisiología del ganado lechero (Belhadi Slimen et al., 2016; Sauvant et al., 2011). El estrés por calor afecta a la mayoría de los aspectos de la función reproductiva en el macho y en la hembra: afectando la tasa de preñez, actividad estral, mortalidad embrionaria y características espermáticas como la motilidad, viabilidad y morfología (Belhadj Slimen et al., 2016; Marai et al., 2007; Hansen, 2009). Además, durante el final de la gestación puede comprometer el crecimiento del feto, afectar la absorción postnatal de inmunoglobulinas del calostro y tener acciones a largo plazo que resultan en una reducción de la producción de leche cuando el ternero se convierte en adulto (Hansen 2020; Dahl et al., 2019). Finalmente, un estrés por calor extremo a veces conduce a la muerte (Bishop-Williams et al., 2015; Vitali et al., 2015).

La tolerancia al calor se define como la capacidad de los animales para mantener la expresión de su potencial funcional heredado por el genotipo cuando se crían en condiciones de calor y humedad. La base fisiológica de la tolerancia al calor incluye una gran área de piel a una relación de peso vivo, piel pigmentada y párpados, ojos protegidos y una capa corporal de color claro o blanco. Los animales tolerantes al calor ambiental también deben poder caminar largas distancias, adaptarse a una ingesta baja de agua y a una ingesta alta de sales (en el agua potable o en el forraje), así como a alimentos de mala calidad nutricional propios de los trópicos (Belhadi Slimen et al., 2016).

El seguimiento y análisis de los parámetros reproductivos y productivos conducen a una mejor comprensión de los procesos de adaptación del genotipo a condiciones de trópico esto puede ayudar a determinar también el riesgo del cambio climático y sus efectos sobre las características de rendimiento reproductivo y en producción de leche (Herbut et al., 2019). La magnitud de la respuesta del animal a temperaturas ambientales elevadas está definida por la especie y genotipo de ganado y su estado fisiológico (Belhadj Slimen et al. 2016). Entre las especies de ganado, se informó que las cabras eran las que mejor toleraban las temperaturas ambientales elevadas (Belhadi Slimen et al., 2016). De manera similar, los animales autóctonos criados en regiones tropicales y áridas están más adaptados al clima cálido que los que viven en ambientes templados (Belhadj Slimen et al., 2016; Marai et al., 2007). Los rumiantes gestantes y lactantes son más susceptibles al estrés por calor que las no gestantes y no lactantes (Belhadi Slimen et al., 2016) Los animales seleccionados por su alto potencial de producción son menos tolerantes a la carga de calor que los animales con bajo potencial de producción (Belhadj Slimen et al., 2016; Sauvant et al., 2011)

El cambio climático global significa que las limitaciones a la producción ganadera sostenible causadas por el estrés por calor serán incluso más importantes que en la actualidad (Battisti and Naylor, 2009; Gauly et al., 2013). También aumentará la selección genética para los rasgos de producción como la producción de leche y la tasa de crecimiento que están asociados con una mayor producción de calor metabólico debido al cambio asociado en el equilibrio térmico (Hansen, 2020). El ganado, al igual que otros mamíferos, son homeotermos que poseen una variedad de mecanismos de adaptación que pueden activarse durante el estrés por calor para regular la producción metabólica de calor y el intercambio de calor con el medio ambiente (Bernabucci et al., 2010; Berman, 2019). La activación de algunos de estos mecanismos, como la reducción de la ingesta de pienso o la redistribución del flujo sanguíneo, pueden provocar efectos adversos sobre la reproducción, salud y la productividad. Además, cuando las adaptaciones fisiológicas son insuficientes para prevenir la hipertermia durante el estrés por calor, la función celular se ve comprometida y los efectos adversos adicionales se derivan de la consiguiente alteración de la función celular (Hansen, 2020).

Los eventos reproductivos son particularmente sensibles a los efectos del choque térmico. El ovocito (Roth, 2018), como el embrión preimplantado (Hansen, 2007), se dañan por la exposición a temperaturas elevadas y la espermatogénesis se interrumpe a temperaturas testiculares elevadas (Hansen, 2020). No está bien establecida la importancia de los efectos directos de la temperatura elevada sobre la función celular como mediador de los efectos del estrés por calor en otros aspectos de la salud y la producción del ganado. Sin embargo, un artículo reciente indica que muchos de los marcadores genéticos de la resistencia de las vacas lecheras a los efectos negativos del estrés por calor en la producción de leche están cerca de los genes del estrés celular (Flori et al., 2019) esto puede significar que la interrupción de la función celular es importante para una gama más amplia de efectos del estrés por calor de lo que a menudo se cree. 
Reportes indican que las razas índicas tienen mejor capacidad para regular la temperatura corporal durante el estrés por calor que el ganado de razas taurinas (Hansen, 2020). También existen diferencias en la capacidad termorreguladora entre razas taurinas específicas. Las razas del hemisferio occidental Senepol y Romosinuano muestran temperaturas rectales más bajas durante el estrés por calor que Angus y Hereford (Hammond et al., 1996; Scharf et al., 2010). La raza Carora, que se derivó en parte de una raza criolla de zona tropical, tienen temperaturas rectales más bajas durante el estrés por calor que la raza Holstein (Olson et al., 2003). Asimismo, se ha reportado la capacidad termorreguladora entre la raza Simmental (Norte de Europa) es superior a la raza Angus (Rocha et al. 2019) y la Jersey superior a Holstein (Liang et al. 2013).

El ganado doméstico ha adquirido mutaciones genéticas que les ayudan a adaptarse al entorno local en el que evolucionaron. También existe una variabilidad genética en la capacidad de regular la temperatura corporal entre razas. Las estimaciones de heredabilidad de la temperatura rectal durante el estrés por calor en el ganado lechero varían de 0,13 a 0,17 (Dikmen et al., 2012; Otto et al., 2019) mientras que las estimaciones en el ganado de carne varían entre 0,22 y 0,68 (Hansen, 2020; Sarlo Davila et al., 2019; Howard et al., 2014; Porto-Neto et al., 2014; Hamblen et al., 2018). Un problema con la selección genética para las bajas temperaturas corporales durante el estrés por calor en el ganado lechero es que la temperatura rectal se correlaciona negativamente con la reproducción y producción de leche (Dikmen et al. 2012).

En condiciones de climas tropicales como el de Madre de Dios, los bovinos lecheros poseen una baja y diferenciada producción de leche que va desde los 2 a 8 litros de leche por día y esto según la estación en la que se encuentre, aumentando la producción en la estación lluviosa (Arias et al., 2008). Existen reportes de experiencias de ganaderos de la zona de Tambopata en Madre de Dios al introducir ganado Holstein Friesian, con malos resultados ya que el $80 \%$ de estos murieron por no poderse adaptar al clima teniendo como consecuencia estrés calórico y un nivel inmunológico bajo, alta infestación de garrapatas y patologías como Anaplasmosis y Piroplasmosis que los llevaron a la muerte (Arias et al., 2008). Esto hace pensar que el factor de adaptabilidad de la hembra bovina a la región va depender de las características genotípicas del animal y están afectadas por factores fisiológicos y celulares siendo una necesidad evaluar y analizar la adaptabilidad de animales lactopoyéticos a la región de Tambopata, razón a lo mencionado nos planteamos como objetivo evaluar el desempeño reproductivo como respuesta de adaptabilidad a las condiciones de manejo y climáticas de Madre de Dios, para los genotipos Brown Swiss y Mestizo.

\section{MATERIALES Y METODOS}

Ubicación geográfica y condición climática de la región de estudio Los animales de estudio se mantuvieron en el Centro de Desarrollo Ganadero de Madre de Dios (CEDEGA), sector Castañal, Distrito y Provincia de Tambopata, geográficamente ubicado a una altitud de 219 metros sobre el nivel del mar a $12^{\circ} 38^{\prime} 30,29^{\prime \prime}$ de latitud Sur y $69^{\circ} 17^{\prime} 03,52^{\prime \prime}$ longitud oeste. El clima de Madre de Dios es de tipo tropical; cálido, húmedo y con precipitaciones superiores a $1000 \mathrm{~mm}$ anuales. La temperatura media anual en Puerto Maldonado, es de $38^{\circ} \mathrm{C}$. En los meses de agosto y setiembre el clima de Madre de Dios sufre a veces influencias de masas de aire frío que llegan desde el sureste del continente americano ocasionando sensibles bajas de temperatura que hacen bajar el termómetro hasta $8^{\circ} \mathrm{C}$ (Uchasara et al. 2020).

\section{Unidades de estudio y Manejo de los animales}

Setenta y ocho animales fueron evaluados, considerando a cada uno como unidad experimental, registros e historiales reproductivos sirvieron para la tabulación de los eventos evaluados divididos en dos tratamientos según el genotipo de estudio; 40 vaquillas del genotipo Brown Swiss y 38 vaquillas Mestizas. Los animales Brown Swiss fueron animales Puros por Cruce (PPC) procedentes del Departamento de Puno que llegaron al CEDEGA de Madre de Dios con el fin de proporcionar material genético a la ganadería lechera de la zona de Tambopata, evaluándose en estos animales la respuesta reproductiva a las condiciones de manejo y climáticas del trópico húmedo de Madre de Dios. Las vaquillas mestizas son animales criados bajo las condiciones ambientales y de manejo del mismo centro. El manejo reproductivo aplicado en su totalidad fue a través de la inseminación artificial (IA).

Todos los animales se mantuvieron en un corral abierto con piso de tierra. El corral y los potreros contaban con cobertizo y una sombra de árboles para proteger a las vaquillas de la radiación solar directa. Se alimentó al pastoreo, ad libitum, con forraje verde compuesto por pasto Marandú (Brachiaria brizantha $\mathrm{cv}$ marandú), Brizanta (Brachiaria brizantha) y pasto Camerún en 30 hectáreas distribuidos en 6 potreros. Se les suplementó concentrado durante la estabulación (130 kg/día), la mezcla de concentrado consistió en $20 \%$ de proteína cruda y $70 \%$ de nutrientes digeribles totales, para proporcionar suplementación isonitrogenadas e isoenergéticas. Se puso a disposición de todas las vacas sales minerales, agua fresca y limpia para beber durante el día. Durante el experimento, se siguió una gestión sanitaria de rutina para garantizar que las vacas no tuvieran ningún trastorno de salud asimismo todos los animales del estudio fueron inmunizados con carbunclo y rabia realizándose pruebas de descarte de tuberculosis y brucelosis según el plan sanitario.

\section{Cálculo e interprefación de indicadores reproductivos y productivos}

Para la obtención y seguimiento de indicadores se utilizó una libreta de campo en la cual se registró detalladamente cada variable del desempeño reproductivo del animal bajo estudio (fecha de celo, Nro. de servicios, entre otras) según identificación del bovino, luego se procedió a sostener una base de datos como matriz, realizada la sistematización de indicadores reproductivos se obtuvo la matriz de resultados mediante hoja de cálculo Excel de Microsoft Office 365. Los indicadores reproductivos investigados fueron: edad al primer celo de vaquillas (calculando meses transcurridos desde el nacimiento hasta el primer celo detectado), edad al primer parto (determinando meses trascurridos del nacimiento al primer parto), Intervalo parto primer servicio (días transcurridos desde el parto al primer servicio, luego de un periodo de espera voluntario de 60 días), Intervalo parto preñez o días abiertos (calculando días transcurridos desde el parto al diagnóstico de preñez), servicios por preñez (Nro. de Inseminaciones hasta la confirmación de preñez) y se cuantificó 
tasa de preñez siguiendo el método descrito por Olivera ( 2010).

\section{Análisis estadístico}

Las variables edad al primer celo de vaquillas, edad al primer parto, intervalo parto primer servicio e intervalo parto preñez se analizaron con medidas de tendencia central (media) y dispersión (desviación estándar), en tanto las variables servicios por preñez y tasa de preñez mediante un análisis de frecuencia (frecuencia observada y porcentual).

Las variables de edad al primer celo, edad al primer parto, intervalo parto primer servicio, e intervalo parto preñez se determinaron como continuas y se evaluaron con t de Student utilizando el Software SPSS ver 23. El número de servicios por preñez se utilizó como variable discontinua y la preñez por IA como variable binomial. La prueba $\chi^{2}$ de independencia se utilizó para detectar diferencias en el número de servicios por preñez y preñez al primer servicio, en todos los casos las diferencias estadísticas se declararon en un nivel de significancia de $\alpha=0,05$.

\section{RESULTADOS}

La edad a primer celo de las vaquillas Brown Swiss fue de $12,43 \pm 0,84$ meses, mientras que en el ganado mestizo fue de
18,68 $\pm 0,99$ meses, presentando diferencia estadística significativa $(P<0,05)$. Los resultados muestran que el genotipo Brown Swiss tiene un desarrollo a la pubertad mucho más temprano, encontrándose dentro de la edad óptima. La edad de la primera servicio (inseminación artificial) de las vaquillas Brown Swiss fue de 15,88 $\pm 2,51$ meses, mientras que en el ganado mestizo $18,68 \pm 0,99$ meses existiendo diferencia estadística significativa $(P<0,05)$.

La edad promedio a la pubertad para ganado Brown Swiss en clima tropical se encuentra dentro de los parámetros reproductivos establecidos por Nieto (1993) quien reporta un valor óptimo de edad al primer celo es menor a 12 meses. La edad al primer parto de las vacas Brown Swiss fue de 25,25 $\pm 2,67$ meses, mientras en el ganado mestizo fue de $28,34 \pm$ 1,71 meses, observándose diferencia estadística significativa $(\mathrm{P}<0.05)$.

En este estudio número de servicios por preñez y tasa de preñez en el ganado Brown Swiss y genotipo Mestizo se encontró dentro de los parámetros reportados por la literatura. En Tabla 1, se observa todos los indicadores estudiados para evaluar la performance reproductiva en el genotipo Brown Swiss y mestizo criado en condiciones de trópico húmedo.

Tabla 1. Performance reproductiva en vacas Brown Swiss y mestizo criados en trópico húmedo

\begin{tabular}{lccccc}
\hline \multicolumn{1}{c}{ Indicador } & $\mathrm{n}$ & Brown Swiss & $\mathrm{n}$ & Mestizo & Dif. significativa \\
\hline Edad promedio a primer celo (meses) & 40 & $12,43 \pm 0,84$ & 38 & $18,68 \pm 0,99$ & $\mathrm{P}<0,05$ \\
Edad promedio del primer parto (meses) & 40 & $25,25 \pm 2,67$ & 38 & $28,34 \pm 1,71$ & $\mathrm{P}<0,05$ \\
Intervalo parto al primer servicio (días) & 40 & $99,29 \pm 20,09$ & 38 & $152 \pm 9.57$ & $\mathrm{P}<0,05$ \\
Intervalo parto preñez o días abiertos (días) & 40 & $107,29 \pm 14,50$ & 38 & $162 \pm 12.50$ & $\mathrm{P}<0,05$ \\
Tasa de Preñez al primer servicio (\%) & 40 & $70.0 \%$ & 38 & $68,4 \%$ & n.s. \\
Número de Servicios por Preñez & 40 & 1,30 & 38 & 1,39 & n.s. \\
\hline
\end{tabular}

Otros indicadores reproductivos: a pesar de que no fueron objetos de estudio, en el seguimiento reproductivo de la aclimatación se observó que el $10,0 \%$ de las vacas Brown Swiss tuvieron incidencias de abortos, mientras que solo el $5,3 \%$ del ganado mestizo presentaron abortos $(P>0,05)$. Además, raza local mestiza mostró porcentajes más bajos de infestación o problemas de garrapatas registrados durante el periodo de estudio, reportamos problemas de Piroplasmosis en el $100 \%$ de los semovientes Brown Swiss presentando síntomas de fiebre y anemia que junto con el estrés calórico son posible causales de los abortos registrados.

Los problemas de retención de placenta fueron de $15,0 \%$ y $13,2 \%$ en las vacas Brown Swiss y mestiza, respectivamente. Siendo este valor más alto a lo recomendado por Nieto (1993).

Tabla 2. Otros indicadores reproductivos observados

\begin{tabular}{lccccc}
\hline \multicolumn{1}{c}{ Indicador } & $\mathrm{n}$ & $\begin{array}{c}\text { Brown } \\
\text { Swiss }\end{array}$ & $\mathrm{n}$ & Mestizo & $\begin{array}{c}\text { Dif. } \\
\text { Signif. }\end{array}$ \\
\hline Abortos (\%) & 40 & $10,0 \%$ & 38 & $5,3 \%$ & n.s. \\
$\begin{array}{l}\text { Retención de } \\
\text { Placenta (\%) }\end{array}$ & 40 & $15,0 \%$ & 38 & $13,2 \%$ & n.s. \\
$\begin{array}{l}\text { Infección Uterina } \\
(\%)\end{array}$ & 40 & $17,5 \%$ & 38 & $7,9 \%$ & n.s. \\
\hline
\end{tabular}

\section{DISCUSIÓN}

La aclimatación es un proceso mediante el cual los animales se adaptan a las condiciones ambientales y se involucran en cambios de comportamiento, hormonales y metabólicos que son características de la homeostasis de aclimatación o de los mecanismos homeoréticos utilizados por los animales para sobrevivir en un nuevo "estado fisiológico" y en "nuevo ambiente", donde básicamente las condiciones de calor y humedad repercutirán en el metabolismo fisiológico para la determinación de la performance reproductiva. Las alteraciones en el perfil hormonal se caracterizan principalmente por un descenso y un aumento de las hormonas anabólicas y catabólicas, respectivamente. La respuesta a la carga de calor y al cambio inducido por el calor en los modificadores homeoréticos altera la energía post absorbente, el metabolismo de lípidos y proteínas, deteriora la función hepática, causa estrés oxidativo, pone en peligro la respuesta inmunitaria y disminuye el rendimiento reproductivo. Estas modificaciones fisiológicas alteran la distribución de nutrientes y pueden evitar que las vaquillas y vacas lactantes con estrés por calor recluten mecanismos ahorradores de glucosa a pesar de la ingesta reducida de nutrientes dependiendo de ello su expresión productiva y reproductiva según el genotipo de ganado (Bernabucci et al., 2010). 
En este estudio la edad al primer servicio de ganado Brown Swsiss fue superado por lo reportado por Zárate-Martínez et al. (2010) de 30 meses, Casas Seas (2017) de 16,58 $\pm 2,34$ meses y Catari Macedo (2018) de 23,00 \pm 5,00 meses. Asimismo, la edad a primer parto para la raza Brown Swiss reportado en este estudio fue superado por lo publicados por Catari Macedo (2018) de 35,00 $\pm 6,70$ meses, Casas Seas (2017) de 40,13 $\pm 7,07$ meses, Coaquira (2019) de 36,95 meses, Deza Calsín (2007) de 37,44 $\pm 8,03$ meses y Olaguivel Flores (2006) de 36,41 $\pm 13,72$ meses.

La duración del intervalo parto preñez es influenciada por varios factores ambientales, genéticos, fisiológicos y metabólicos como son: raza, estado nutricional, amamantamiento, producción de leche, frecuencia de ordeño, rendimiento de leche real y potencial genético. La duración también es influenciada por la rapidez de involución uterina, la rapidez de desarrollo de los folículos ováricos, las concentraciones hormonales y los cambios en el peso corporal y consumo de energía. En vacas, el balance energético en los primeros 20 días de lactación es importante para determinar el inicio de la actividad ovárica posparto. En este estudio, el intervalo parto preñez o días abiertos observado en las vacas Brown Swiss fue de 107,29 $\pm 14,50$ días. Si se apunta a un intervalo entre partos de 13,6 meses, los días abiertos (intervalo parto-preñez) no deben sobrepasar de 134 a 135, en promedio (Olivera, 2010). Deza Calsin (2007) reportó valores de $109 \pm 66,41$ días para el intervalo entre el parto y el primer servicio, y de $145,12 \pm 88.06$ días de intervalo parto concepción de vacas Brown Swiss.

En los últimos años, ha habido un aumento en algunos parámetros reproductivos y cambios fisiológicos en los animales lactopoyéticos, como resultado de estos cambios ambientales durante el período de 1980 a 2000 . El intervalo entre partos aumentó de menos de 13 meses a más de 14,5 meses, asimismo, el número de inseminaciones por vaca aumentó de 2,0 a 3,5. Estos cambios se produjeron junto con una disminución neta de las tasas de preñez de la primera IA/servicio en un 0,5\% por año (Oltenacu and Algers 2005). Así mismo algunos indicadores sanitarios entre ellos se incluye a la endometritis que aumentó de una frecuencia de rebaño de $38,1 \%$ a $46 \%$ y de $25,5 \%$ a $30,1 \%$ en vacas primíparas y multíparas, respectivamente (Honig et al., 2016).

Intervalo del parto a la primera inseminación en las vacas Brown Swiss fue de 99,29 $\pm 20,09$ días. Similar resultado reportó Deza Calsin (2007) con valores de $109 \pm 66,41$ días. Esto podría atribuirse a una irregularidad en la disponibilidad de alimento a lo largo del año, que disminuye la condición corporal de los animales provocando un retardo en el reinicio de la actividad ovárica.

Una alta tasa de producción de leche expone a las vacas a una carga metabólica mayor. Además, los cambios climáticos y el calentamiento global provocaran una elevación de los niveles de estrés por calor a los que están expuestas las vacas en la etapa de producción especialmente durante el verano (Honig et al., 2016). El incremento del estrés metabólico como del estrés por calor puede ser la causa subyacente del aumento o alteración de los indicadores de evaluación de la performance reproductiva y de la incidencia de patologías reproductivas en los sistemas de reproducción de leche y más aún si no se usa el genotipo acorde para la región del trópico en Madre de Dios y Tambopata.

El ganado Brown Swiss presentó un desarrollo a la pubertad mucho más temprano, logrando tener una cría en menor tiempo, esto se refleja en los resultados obtenidos en la edad promedio del primer celo en vaquillas Brown Swiss de 12,43 meses; la edad promedio de la primera IA de las vaquillas Brown Swiss de 15,88 meses y la edad promedio del primer parto de las vaquillonas Brown Swiss de 25,25 meses, El genotipo mestizo retardo más en restablecer su actividad ovárica cíclica, esta es la causa principal de lo tardío en el ingreso de la etapa reproductiva reflejada en el prolongado intervalo entre partos (16 a 20 meses), así como la presentación de celos postparto de 5 meses posterior, este factor genotipo se debe por tener genes de razas Bos indicus.

\section{CONCLUSION}

El desempeño reproductivo del genotipo Brown Swiss está dentro los estándares propios de la raza mostrando buena performance reproductiva al Trópico Húmedo, en comparación con los indicadores reproductivos de animales mestizos.

\section{Código de Ética}

Los autores declaran que el estudio presentado se ha llevado a cabo de acuerdo con el código de Ética para los experimentos con animales, tal y como se refleja en la normativa:

http://ec.europa.eu/environment/chemicals/lab_animals/legi sl ation_en.htm.

\section{Conflictos de intereses}

Los autores firmantes del presente trabajo de investigación declaran no tener ningún potencial conflicto de interés personal o económico con otras personas $u$ organizaciones que puedan influir indebidamente con el presente manuscrito.

\section{Contribuciones de los autores}

Preparación y ejecución: RT, JR. Desarrollo de la metodología: RT, CM, JR. Concepción y diseño: JR, CM, RT. Edición del artículo: JR, RT, CM. Supervisión del estudio: JR

\section{REFERENCIAS}

1. Arias R, Mader T, Escobar P. Factores climáticos que afectan el desempeño productivo del ganado bovino de carne y leche. Archivos de Medicina Veterinaria, 2008; 40: 7-22. $\quad \mathrm{http}: / / \mathrm{dx}$.doi.org/10.4067/S0301 $732 \times 2008000100002$.

2. Battisti D, Naylor R. Historical warnings of future food insecurity with unprecedented seasonal heat. Science, 2009; 323: 240-44.DOI: 10.1126 / science.1164363

3. Belhadi Slimen I, Najar T, Ghram A, Abdrrabba M. J Heat stress effects on livestock: molecular, cellular and metabolic aspects, a review. Journal of Animal Physiology and Animal Nutrition, 2016; 100: 401-12. doi: 10.1111 / ipn.12379.

4. Berman A. An overview of heat stress relief with global warming in perspective. International journal of biometeorology, 2019;63: 493-98. DOI: $10.1007 /$ s00484-019-01680-7 
5. Bernabucci U, Lacetera N, Baumgard LH, Rhoads RP, Ronchi $B$, Nardone A. Metabolic and hormonal acclimation to heat stress in domesticated ruminants. Animal. 2010;4(7): 1167 1183. doi: $10.1017 / \mathrm{S} 175173111000090 \mathrm{X}$

6. Bishop-Williams KE, Berke O, Pearl DL, Hand K, Kelton DF. Heat stress related dairy cow mortality during heat waves and control periods in rural Southern Ontario from 20102012. BMC Veterinary research, 2015; $11: 1-10$. DOI: 10.1186/s1 2917-015-0607-2

7. Casas Seas AH. Nivel de tecnología e índices productivos y reproductivos de vaquillas Brown Swiss criadas en dos sistemas de producción a $3200 \mathrm{msnm}$. Tesis de Maestría Zootecnia. Universidad nacional del Centro del Perú. 2017. Disponible en: http://repositorio.uncp.edu.pe/handle/20.500.12894/4 814

8. Catari Macedo Y. Eficiencia biológica lechera de vacas Brown Swiss a la primera lactación del CIP Chuquibambilla, años 2010-2016. Tesis de grado. Universidad Nacional del Altiplano. 2018. Disponible en: http://repositorio.unap.edu.pe/handle/UNAP/1 2073.

9. Coaquira J. Eficiencia productiva y económica y perspectivas de las microcuencas lecheras-región Puno. Semestre Económico, 2019; 8: 7-38. https://doi.org/10.26867/seconomico.v8i2.326

10. Dahl GE, Skibiel AL, Laporta J. In utero heat stress programs reduced performance and health in calves. Veterinary Clinics of North America: Food Animal Practice, 2019; 35: 343-53. DOI: 10.1016/i.cvfa.2019.02.005

11. Decker JE, McKay SD, Rolf MM, Kim J, Molina Alcalá A, Sonstegard TS, Hanotte O, Götherström A, Seabury CM, Taylor JF. Worldwide patterns of ancestry, divergence, and admixture in domesticated cattle. PLoS Genet Praharani, 2014; 10: el 004254. https://doi.org/10.1371/journal.pgen.1004254

12. Deza Calsín H. Evaluación de parámetros reproductivos y productivos en vacas Brown Swiss criadas en sistema extensivo. Universidad Nacional Agraria La Molina, Lima (Perú). Escuela de Postgrado. Especialidad de Producción Animal. 2007.

13. Dikmen S, Cole JB, Null DJ, Hansen PJ. Heritability of rectal temperature and genetic correlations with production and reproduction traits in dairy cattle. Journal of Dairy Science, 2012; 95: 3401-05. DOI: 10.3168/ids.201 1-4306

14. Flori L, Moazami-Goudarzi K, Alary V, Araba A, Boujenane I, Boushaba N, Casabianca F, Casu S, Ciampolini R, Gautier M. A genomic map of climate adaptation in Mediterranean cattle breeds. Molecular ecology, 2019; 28: 1009-29. DOI: $10.1111 / \mathrm{mec} .15004$

15. Gauly $M$, Bollwein $H$, Breves $G$, Brügemann $K$, Dänicke $S$, Daș G, Demeler J, Hansen H, Isselstein J, Wrenzycki C. Future consequences and challenges for dairy cow production systems arising from climate change in Central Europe-a review. Animal, 2013; 7 (5), 843-59. DOI: $10.1017 /$ S1751731112002352

16. Blanco JPG, WingChing-Jones R. Producción $y$ reproducción de vacas Holstein, Jersey y sus cruces en cinco localidades de Costa Rica. UNED Research Journal, 2018; $10 \quad(2), \quad$ 422-427. In. http://dx.doi.org/10.22458/uri.v10i2.2171
17. Hamblen H, Hansen PJ, Zolini AM, Oltenacu PA, Mateescu RG. Thermoregulatory response of Brangus heifers to naturally occurring heat exposure on pasture. Journal of animal science, 2018; 96: 3131-37. DOI: 10.1093 /jas/sky224

18. Hammond AC, Olson TA, Chase Jr CC, Bowers EJ, Randel RD, Murphy CN, Vogt DW, Tewolde A. Heat tolerance in two tropically adapted Bos taurus breeds, Senepol and Romosinuano, compared with Brahman, Angus, and Hereford cattle in Florida. Journal of animal science, 1996; 74: 295-303. DOI: 10.2527/1996.742295x

19. Hansen PJ. Effects of heat stress on mammalian reproduction. Philosophical Transactions of the Royal Society B: Biological Sciences, 2009; 364: 3341-50. DOI: 10.1098/rstb.2009.0131

20. Hansen PJ. Prospects for gene introgression or gene editing as a strategy for reduction of the impact of heat stress on production and reproduction in cattle. Theriogenology, 2020; 154: 190-202. DOI: $10.1016 / \mathrm{i}$.theriogenology.2020.05.010

21. Hansen PJ. To be or not to be determinants of embryonic survival following heat shock. Theriogenology, 2007; 68: S40-S48. DOI: 10.1016/i.theriogenology.2007.03.013

22. Herbut P, Angrecka S, Godyń D, Hoffmann G. The physiological and productivity effects of heat stress in cattle-a review. Annals of Animal Science, 2019; 19: 579 . 93. https://doi.org/10.2478/aoas-2019-0011

23. Honig $H$, Ofer L, Kaim M, Jacobi S, Shinder D, Gershon E. The effect of cooling management on blood flow to the dominant follicle and estrous cycle length at heat stress. Theriogenology, 2016; 86: 626-34. DOI: 10.1016/i.theriogenology.2016.02.017

24. Howard JT, Kachman SD, Snelling WM, Pollak EJ, Ciobanu DC, Kuehn LA, Spangler ML. Beef cattle body temperature during climatic stress: a genome-wide association study. International journal of biometeorology, 2014; 58: 1665 72. DOI: $10.1007 /$ S00484-013-0773-5

25. Liang D, Wood CL, McQuerry KJ, Ray DL, Clark JD, Bewley, J.M. Influence of breed, milk production, season, and ambient temperature on dairy cow reticulorumen temperature. Journal of Dairy Science, 2013.96: 5072-81. DOI: 10.3168/ids.2012-6537

26. Mader TL, Davis MS, Gaughan JB. Effect of sprinkling on feedlot microclimate and cattle behavior. International Journal of Biometeorology, 2007; 51: 541- 51. DOI: 10.1007/s00484-007-0093-8

27. Marai IFM, El-Darawany AA, Fadiel A, AbdelHafez MAM. Physiological traits as affected by heat stress in sheep-a review. Small ruminant research, 2007; 71: 1-12. https://doi.org/10.1016/i.smallrumres.2006.10.003

28. Moreno AJ. Evaluación técnica y económica de la producción animal. Universidad Nacional Agraria la Molina, 2005.

29. Nieto R. El control de la Producción (Parte II) manejo. México, 1993.

30. Olaguivel Flores CA. Determinación de los índices reproductivos y productivos de vacas Brown swiss del CIP Chuquibambilla-Puno (1990-2002). Universidad Nacional Agraria La Molina, Lima (Perú). Escuela de Post Grado, Especialidad en Producción Animal, 2006. 
31. Olivera SJ. Midiendo y monitoreando la reproducción en vacas lecheras: La tasa de preñez. Boletín Informativo El Poronguito, 2010.

32. Olson TA, LucenaC, Chase Jr CC, Hammond AC. Evidence of a major gene influencing hair length and heat tolerance in Bos taurus cattle. Journal of Animal Science, 2003; 81 : 80-90. DOI: 10.2527/2003.81180x

33. Oltenacu PA, Algers B. Selection for increased production and the welfare of dairy cows: are new breeding goals needed? AMBIO: A Journal of the Human Environment, 2005; 34: $311-15$.

34. Otto PI, Guimarães SE, Verardo LL, Azevedo ALS, Vandenplas J, Sevillano CA, Marques DBD, Pires MA, De Freitas $F$, Verneque RS. Genome-wide association studies for heat stress response in Bos taurus $\times$ Bos indicus crossbred cattle. Journal of dairy science, 2019; 102: 8148-58. DOl: 10.3168/ids.2018-15305

35. Palacios Espinosa A, Espinoza Villavicencio JL, Menéndez Buxadera, A. Parámetros genéticos para peso al destete y rasgos reproductivos en ganado cebú de Cuba. Nova scientia, 2019; 11: 1-25. https://doi.org/10.21640/ns.v1 1i22.1672

36. Porto-Neto LR, Reverter A, Prayaga KC, Chan EK, Johnston DJ, Hawken RJ, Fordyce G, Garcia JF, Sonstegard TS, Sunduimijid B, Goddard ME. The genetic architecture of climatic adaptation of tropical cattle. Plos one, 2014; 9: e 113284 . DOI: 10.1371 /journal.pone.0113284

37. Quinteros-Pozo R, Marini PR. Evaluación productiva y reproductiva de cuatro genotipos lecheros en pastoreo libre en la Amazonía ecuatoriana. Revista veterinaria, 2017; 28: 9-13. http://dx.doi.org/10.30972/vet.2811290

38. Rocha $R$, Baena $M$, de Cássia Estopa A, Gervásio IC, Ibelli A, Gionbelli T, Gionbelli $M$, de Freitas $R$, Meirelles $S$. Differential expression of HSFl and HSPA6 genes and physiological responses in Angus and Simmental cattle breeds. Journal of thermal biology, 2019; 84: 92- 98. DOI: 10.1016/i.jtherbio.2019.06.002

39. Roth Z. Symposium review: Reduction in oocyte developmental competence by stress is associated with alterations in mitochondrial function. Journal of dairy science, 2018; 101: 3642-54. DOI: 10.3168/ids.201713389

40. Sarapura Alzamora ME. Eficiencia reproductiva de vacas de la raza brown swiss en crianza semi intensiva del establo Hualianta Matahuasi-provincia de Concepción $\begin{array}{llll}\text { años } & 2005 & 2010 . & 2014 .\end{array}$ http://hdl.handle.net/20.500.12894/1834

41. Sarlo Davila K, Hamblen H, Hansen PJ, Dikmen S, Oltenacu $P$, Mateescu R. Genetic parameters for hair characteristics and core body temperature in a multibreed BrahmanAngus herd. Journal of animal science, 2019; 97: 3246-52. Doi 10.1093/jas/skz 188

42. Sauvant D, Van Milgen J, Faverdin P, Friggens N. Modelling nutrient digestion and utilisation in farm animals. Springer Science \& Business Media, 2011 . ISBN: 978-90-8686-71 27. https://doi.org/10.3920/978-90-8686-712-7

43. Scharf B, Carroll J, Riley D, Chase JC, Coleman S, Keisler $D$, Weaber R, Spiers D. Evaluation of physiological and blood serum differences in heat-tolerant (Romosinuano) and heat-susceptible (Angus) Bos taurus cattle during controlled heat challenge. Journal of animal science, 2010; 88: 2321-36. DOI: 10.2527/ias.2009-2551Z

44. Uchasara H, Araoz E, Ramos N, Loayza K. Actitudes hacia la conservación ambiental en adolescentes de educación secundaria en Madre de Dios, Perú. Ciencia Amazónica, 2020; 8: 99-1 10. https://doi.org/10.22386/ca.v8i1.283

45. Vallone R, Camiletti E, Exner M, Mancuso W, Marini P. Análisis productivo y reproductivo de vacas lecheras Holstein, Pardo Suizo y sus cruzas en un sistema a pastoreo. Revista Veterinaria, 2016; 25: 40-44. http://dx.doi.org/10.30972/vet.251547

46. Vitali A, Felici A, Esposito S, Bernabucci U, Bertocchi L, Maresca C, Nardone A, Lacetera N. The effect of heat waves on dairy cow mortality. Journal of dairy science, 2015; 98: 4572-79. DOI: 10.3168/ids.2015-9331

47. Zárate-Martínez J, Esqueda-Esquivel V, Vinay-Vadillo J, Jácome-Maldonado SM. Evaluación económico-productiva de un sistema de producción de leche en el trópico. Agronomía Mesoamericana, 2010; 21: 255-65. https://doi.org/10.15517/am.v21i2.4887 